1970s." Rose is a foil to Vera, who is "always ladylike" and not a conventional feminist despite her efforts to empower female patients with cancer.

Hayter was born in England but later immigrated to Canada with his family. His grandfather and father were both physicians; his mother, a nurse. Initially, Hayter pursued his love of theatre, earning a master's degree in drama at the University of Calgary. He was contemplating a career as a theatre academic when medicine beckoned.

"Medicine was always in the background and what I intended to do." The actual switch in career paths came after a couple of life-changing events.

"Certainly a major [event] was my conversation with the Queen's [University] medical admissions officer, Dr. Dawson Einarson, who was enthusiastic about someone with an arts background entering medicine. Another was being witness to the birth of my daughter Rosalind and the wonder at the complexity of it all."

As a medical student, Hayter decided to specialize in radiation oncology after working at a cancer centre and being impressed by the staff.
"They were kind, compassionate people and I was just kind of naturally drawn to them. I thought this was something I would love to do."

Hayter went on to discover that choosing medicine did not have to mean abandoning drama. "The practice of medicine is theatrical," he says again. "I've always felt that, from the time I first started working as a doctor."

Paul Gessell

Art critic

Ottawa, Ont.

CMAJ 2014. DOI:10.1503/cmaj.140812

\title{
POETRY
}

\section{Shifting intimacies}

After all these years,

I'm showering with my wife

again.

The washing away of sweat and sleep.

Every morning

cleansing her body.

The running of water

and sunlight in the room.

The pain in her back grew

and the doctor said

"It's just arthritis."

She coughed and an x-ray

showed the white, white spots.

And then they all knew.

Her spine cracked and they all knew

there was nothing

but waiting and loving and pain and goodbyes.

The heat of breath released in night air.

After all these years, the shower pounding rhythmically against two bodies again.

\section{Marie O'Connor BSc MA}

Second-year medical student

Department of Medicine

University of British Columbia

Vancouver, BC

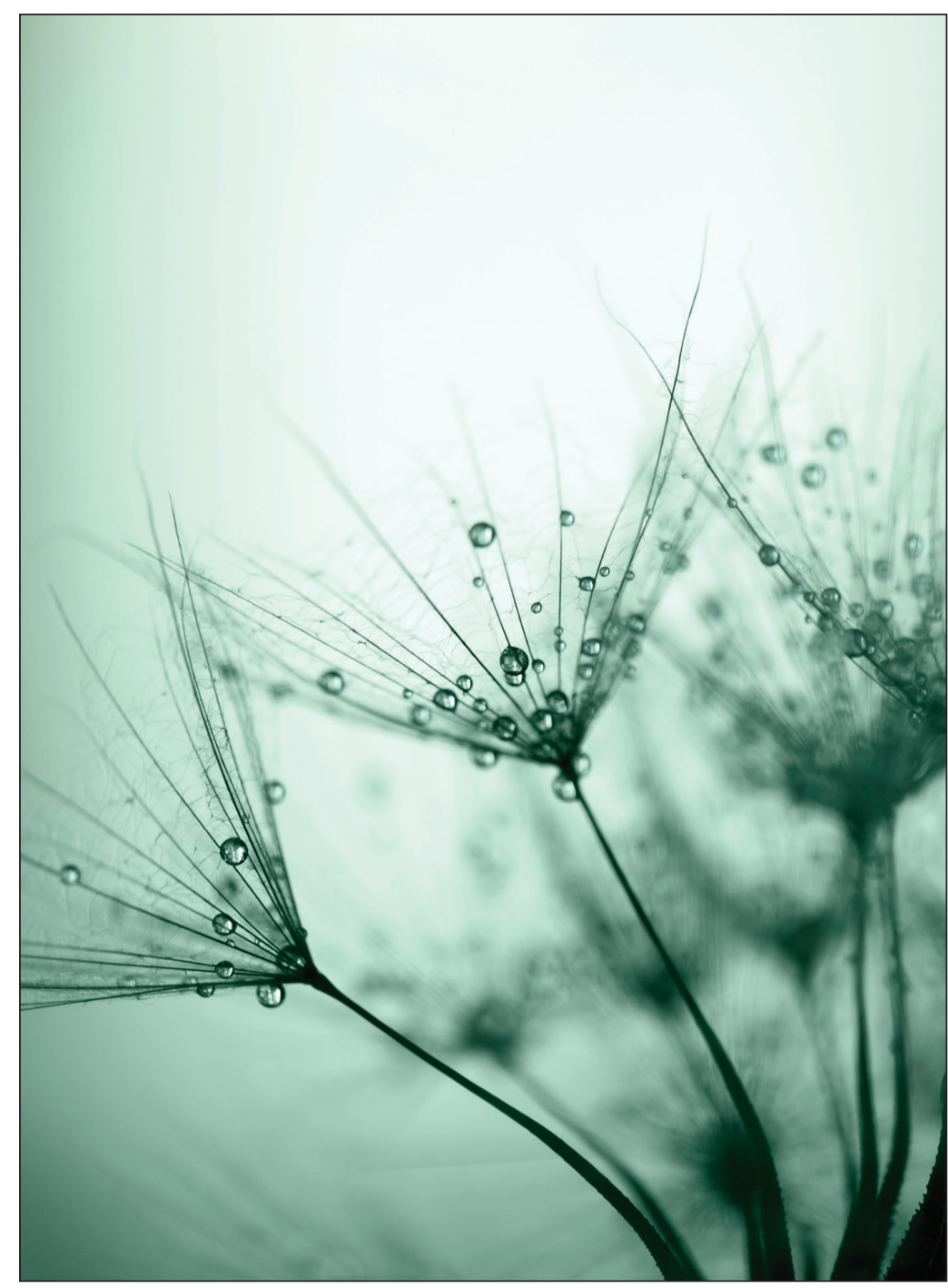

